\title{
Comparative Geospatial Planning Model for "Location Specific" Intervention and Continuous Improvement Strategy
}

\author{
Princewill Ode Odum¹, Nathaniel Olugbade Adeoye², Eleojo Oluwaseun Abubakar, \\ Marcus Aja Idoko ${ }^{1}$ \\ ${ }^{1}$ Department of Geography and Environmental Science, University of Calabar, Calabar, Nigeria \\ ${ }^{2}$ Department of Geography, Obafemi Awolowo University, Ile-Ife, Nigeria \\ ${ }^{3}$ Department of Geography and Planning, Kogi State University, Ayangba, Nigeria \\ Email:princewill@unical.edu.ng,nadeoye@yahoo.com,info4ele@yahoo.com
}

Received 28 January 2016; accepted 10 May 2016; published 13 May 2016

Copyright (C) 2016 by authors and Scientific Research Publishing Inc.

This work is licensed under the Creative Commons Attribution International License (CC BY). http://creativecommons.org/licenses/by/4.0/

c) (i) Open Access

\section{Abstract}

Sustainable development can only be achieved by conscious planning and implementation of action plans. Decision making requires a careful selection of the right conceptual framework and models for planning and implementation processes. Planning process models dictate in very clear terms what must be done and how it is done to achieve a successful completion of a process of activity [1]. Since about $\mathbf{8 0 \%}$ of data used to support decisions are geographically related [3], it is necessary to put Geographic Information Systems (GIS) at the core of the planning and implementation model. There exists a great disparity in a heterogeneous world. The locational disparity in achieving sustainable development, therefore, necessitates a planning model that is "location specific" i.e. identifies areas (locations) requiring intervention and areas (locations) requiring continuous improvement strategies. This was achieved in this study by reviewing Bell's Information System Strategic Planning Model and Kaufman's Strategic Planning Model, and the designing of new model to overcome the limitation of existing models. Practical application of the new model was carried out in education planning and administration in order to achieve the global goals for sustainable development 4 (quality education). Finding shows that the Comparative Geospatial Planning Model for "Location Specific" Intervention and Continuous Improvement Strategy is useful to support the achievement of sustainable development goals in multidisciplinary, multi-sector applicable instances.

\section{Keywords}

Planning, Model, Location, Intervention, Improvement Sustainable Development Goals 


\section{Introduction}

Sustainable development can only be achieved by conscious planning and implementation of action plans. Decision making requires a careful selection of the right conceptual framework and models for planning and implementation processes. The step followed in doing an activity is called "process". Planning process models, therefore provide the steps and necessary actions undertaken (in practice) to achieve an aim. Planning process models dictate in very clear terms what must be done and how it is done to achieve a successful completion of a process of activity [1].

While it is good to "think globally" in a bid to achieve sustainable development, it is expedient to "act locally". The aggregation of individual success in different component of the desired development at different "small scales" would definitely bring about the holistic achievements of the big picture of sustainable development. There exists a great disparity in a heterogeneous world where it is difficult to have a homogenous society. Naqvi [2] wrote about spatial inequality. For example, healthcare, education, water and sanitation, environmental sustainability and all other required components for sustainable development do not necessarily occur in uniform balance across geographic location and socio-economic dynamics. The variation in achievements in these afore mentions development areas therefore necessitates a planning model that is "location specific" i.e. identifying areas (locations) requiring intervention and locations requiring continuous improvement strategies. Since about $80 \%$ of data used to support decisions are geographically related [3], it becomes necessary to put Geographic Information Systems (GIS) at the core of the planning and implementation model.

\section{Aim and Objectives}

The aim of this study is to develop and propound a Comparative Geospatial Planning Model for "Location Specific" Intervention and Continuous Improvement Strategy that would support the achievement of sustainable development goals in simple multidisciplinary, multi-sector applicable instances.

To achieve this aim, the following objectives would be considered:

1) Examine and review existing planning models;

2) Develop a model with a view of improving upon the existing models;

3) Empirically apply the new model in "education" development.

\section{Methodology}

The general method for this empirical study include review of existing planning models (Bell's Information System Strategic Planning Model and Kaufman's Strategic Planning Model), and the design of new model, together with the practical application of the new model. The new model seeks to overcome the limitation of existing models while accentuating their strengths.

Both real life primary and secondary data would be used in the application phase. A GPS receiver would be used to collect coordinates of the point data required for the "location specific" components while existing data on subject of application would be collected from relevant government agency as attribute data. Standard indicators from the sustainable development goals framework would be used as yardstick during analyzed the data using GIS software in order to identify "location specific" interventions as well as plan continuous improvement strategies for complying areas.

\subsection{Review of Existing Planning Models}

It is vitally important to keep in view the related body of existing knowledge before developing a planning model. This paper considers two critical planning models upon which a new planning model is proposed with an aim to improve upon their strengths and eliminate their weakness.

\subsubsection{Bell's Information System Strategic Planning Model}

The Bell's Strategic Planning Model (Figure 1) was developed by Northwest Region Education Laboratory and the Oregon Education Council. This model demonstrates the process required for an effective planning. This planning model consists of 3 major phases:

1) Strategic Planning;

2) Tactical Planning;

3) Control. 


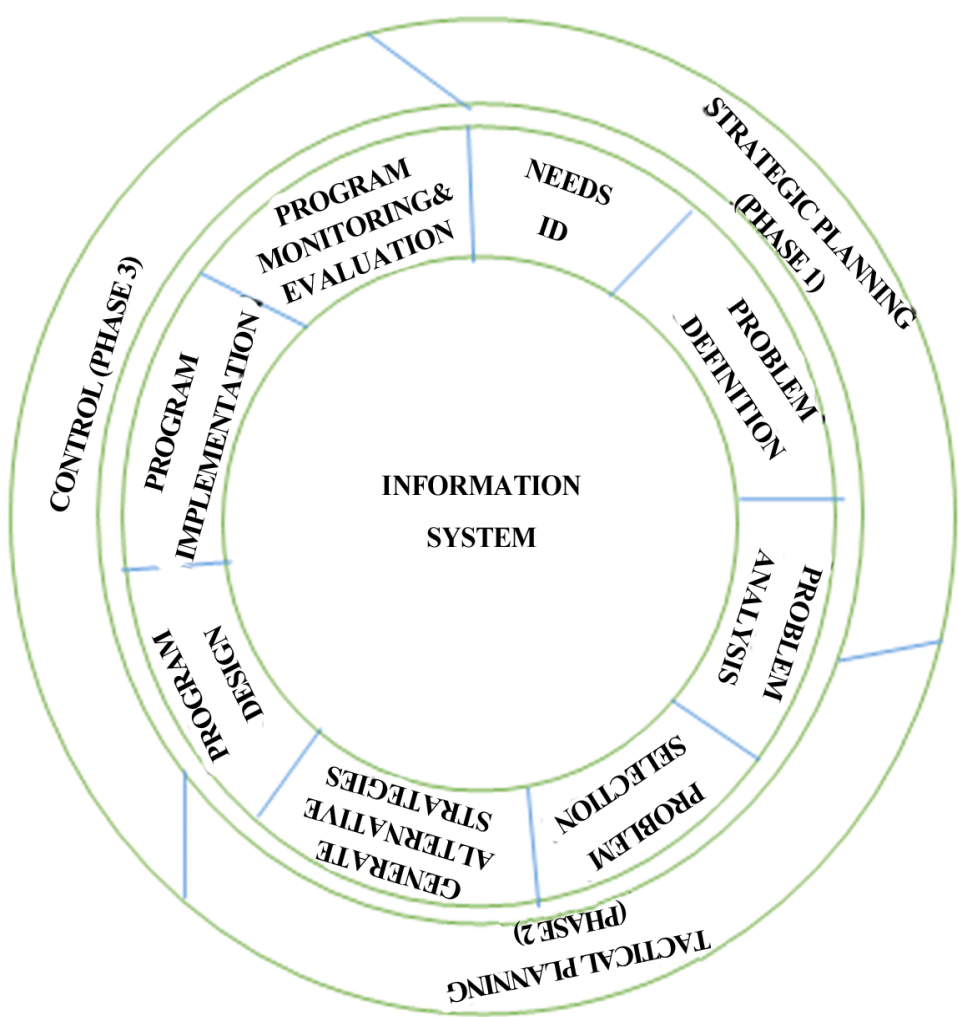

Figure 1. Bell's Strategic Planning Model; Source: Bell et al. cited in [4].

The Bell's strategic planning phase involves problem definition, setting of objectives, and delineation of organized roles and resources. During the Tactical planning phase, set objectives and roles are translated into selection of programs, identification of alternative, and developing specific program designs for action. Control phase ensures that performance proceeds according to plans, as well as monitors and evaluates results. In the center of this circular model is the information system that takes care of all data and information gathered and used as feedback in decision-making and planning process [4].

Though the Bell's Model has an information system component, it still lacks the answers to the "where" questions necessary for location specific implementation, monitoring and control. Hence, there need to develop another model with a Geographic Information System component to support decision making in all sectors of development.

\subsubsection{Kaufman's Strategic Planning Model}

The Kaufman's strategic planning model (Figure 2) has consistently gone through modifications and enhancements. It is a process planning model that starts with scoping, where a clear vision and mission is defined and objectives set after careful needs assessment. The second part of this model is strategic planning. The final part is implementation and continuous improvement. Unlike the Bell's model, Kaufman's strategic planning model lacks an information system necessary for data/information handling, as much as the absence of spatial context necessary for location specific intervention.

These two models (Bell's and Kaufman's) are good framework for strategic planning process upon which this study seeks to build on in developing a GIS based model to support decision. However, the limitation of these existing models includes: monitoring and control based on set objectives instead of comparison with universally accepted standard indicators as yardstick for measuring effectiveness and/or need for continuous improvement, and the absence of geospatial analysis for "location specific" interventions. This study would therefore, improve on existing models by overcoming these limitation in order to provide a Comparative Geospatial Planning Model for "Location Specific" Intervention and Continuous Improvement Strategy model to support decision making based on standard indicators in a spatial context. 


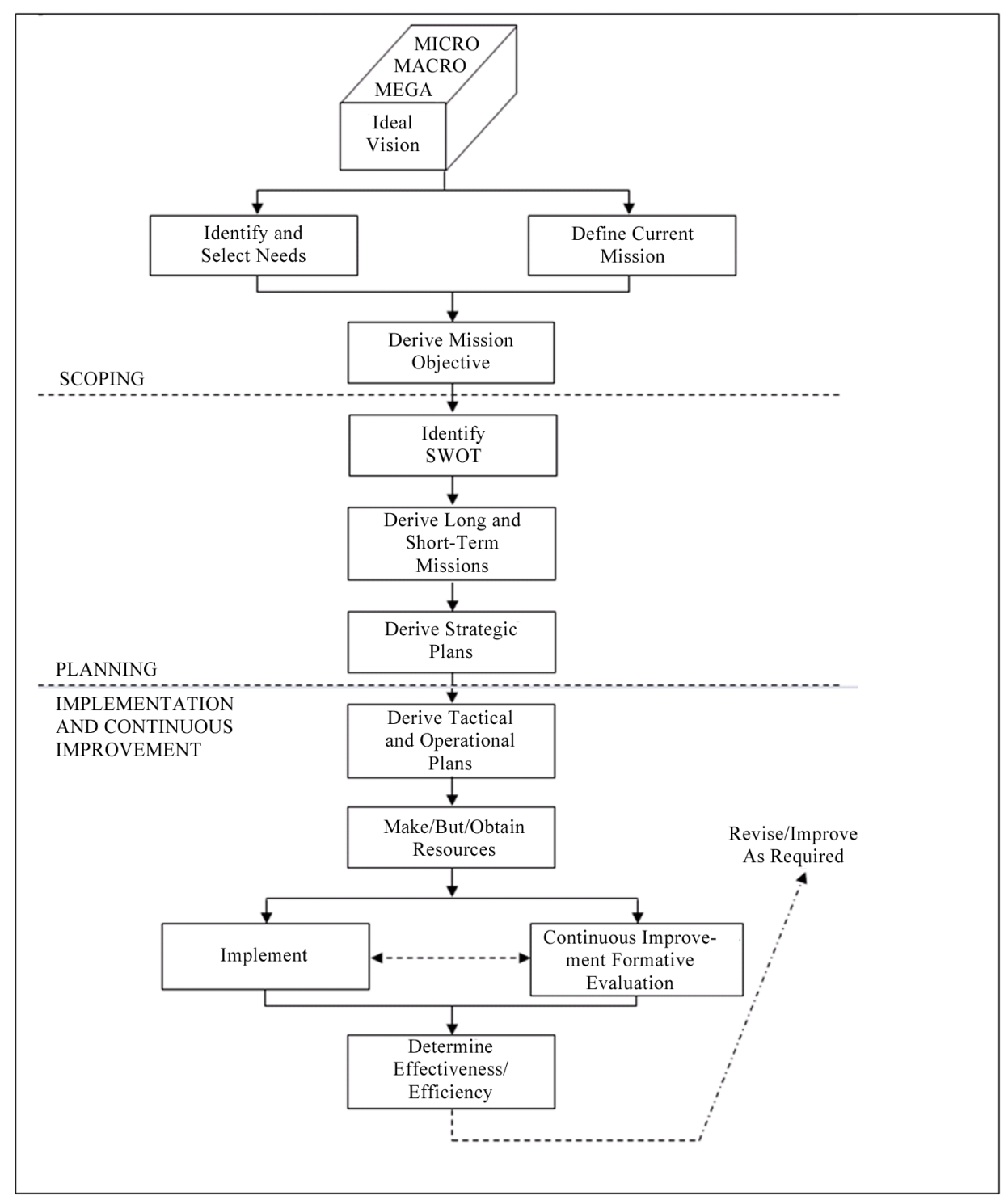

Figure 2. Kaufman strategic planning model. Source: Kaufman et al. cited in [4].

\section{Comparative Geospatial Planning Model for “Location Specific” Intervention and Continuous Improvement Strategy}

Following existing strategic planning models like Bell's and Kaufman's Strategic Planning Models, a GIS based strategic model is hereby developed. The innovative addition is, comparative analysis using globally accepted standard indicators as benchmark, and a geospatial dimension for location specific intervention and continuous improvement strategy. The newly proposed model has three major phases.

Phase 1: Scoping and Planning: This phase involves policy/vision/mission statements; Clear and objective goal setting, outlined action plan.

Phase 2: Data Collection and Processing: This phase requires collection of all relevant data sets (both primary and secondary data), including spatial data (geographic locations/co-ordinates). The data is processed using relevant software that can handle both spatial and non-spatial data (i.e. GIS software, which could be proprietary or open source).

Phase 3: Comparative Analysis for Location Specific Intervention and/or Continuous Improvement Strategy: This last phase involves spatial analysis by comparing with standard globally accepted indicators in order to identify locations requiring intervention and areas requiring continuous improvement strategies. 
Figure 3 is a schematic representation of the "Geospatial Comparative Planning Model for Location Specific Intervention and Continuous Improvement Strategies".

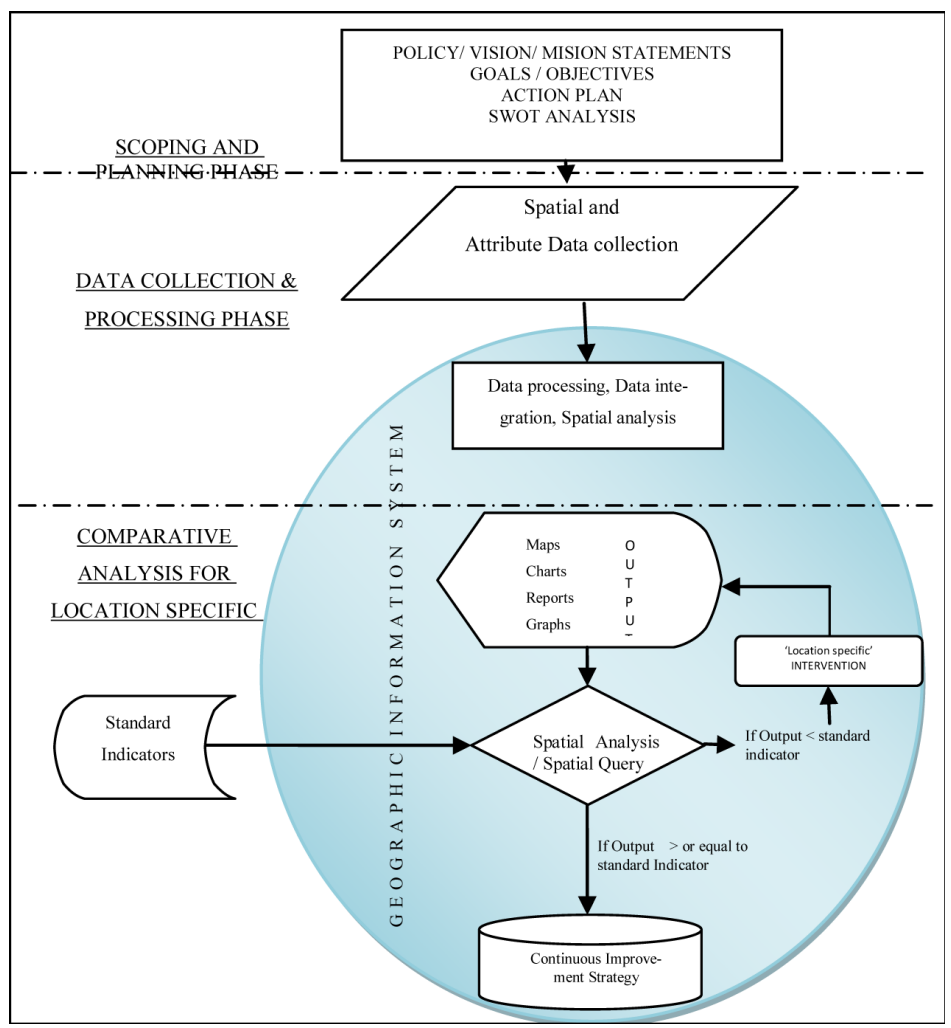

Figure 3. Comparative geospatial planning model for "Location Specific" Interven- tion and continuous improvement strategy.

\section{Application of Model for Sustainable Development Goal (SDG) 4 (A Case Study of Callabar, Cross River State, Nigeria)}

Tibendra [5] demonstrated the applications of GIS as an Education decision Support System (DSS). This makes it appropriate to apply the new GIS based model in Education Administration and Planning. Following the framework of the Comparative Geospatial Planning Model for "Location Specific" Intervention and Continuous Improvement Strategy we have:

PHASE 1: Scooping and Planning

Policy/Vision/Mission Statements: Ensure inclusive and equitable quality education and promote lifelong learning opportunities for all (especially at the universal basic education level).

Targets: By 2030, ensure that all girls and boys have equal access and complete free quality primary with substantially increase in the supply of qualified teachers.

PHASE 2: Data Collection and Processing

Data Collection

1) School Statistics: pupil's enrolment, teachers' statistics, school facilities, etc. from State Ministry of Education;

2) Population Data: from National Population Census [6] [7];

3) Administrative Maps from Ministry of Lands and Survey;

4) GPS Coordinates of schools from Field work using Garmin etrex30 GPS receiver.

Data Processing

1) Data processing: extraction of school age population, computation of basic education ratios of indicators (pupil's teacher ratio, gross enrolment ration, intake rate, gender parity index, etc.);

2) Data Integration: of spatial and non-spatial data sets. 
PHASE 3: Comparative Analysis for "Location Specific" Intervention and/or Continuous Improvement Strategy, using GIS software to carry out spatial analysis, comparing with standard globally accepted indicators.

\section{Results}

The newly developed model was applied in Sustainable Development Goal 4 in the following sub theme to get the following results.

\subsection{Pupil to Teacher Ratio}

"Quality education" is a function of many things. One of such major variables is the ratio of pupils to teacher. UNESCO-UIS [8] [9] estimates a 1.7 million teacher need in Nigeria alone. Taking Calabar being the capital of Cross River state, a spatial analysis query using SQL syntax.

Select from " $"$ " where " $k$ " $\leq x "$ where

$j=$ a Table in the integrated database

$k=$ Table field with calculated indicator for a school

$x=$ identified universally accepted standard indicator or criteria

For example, to support decision on "location specific" intervention, where more teachers are needed; the syntax

Select from "Sch_db Table" where "PTR" $>20$

where

Sch_db Table $=$ school database Table

$\mathrm{PTR}=$ Pupil Teacher Ratio (computed for each schools in the database Table)

$>$ "greater than" = criteria or condition

$20=$ identified universally accepted standard for pupil-to-teacher ratio [10].

A map output (Figure 4) is produced to show school (highlighted in yellow) requiring "location specific" interventions in the area of more teachers to bridge the pupils teacher gap, while the rest schools that satisfy the

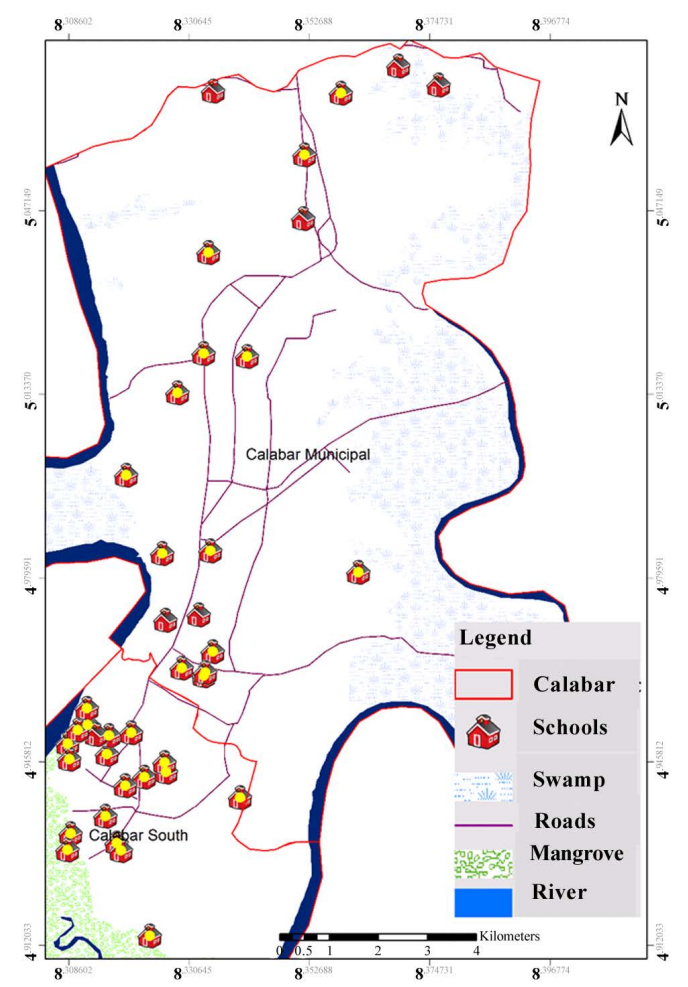

Figure 4. Highlighted Public primary schools (in yellow) where more teachers are needed; Pupil to teacher ratio greater than standard indicator $(P T R)>20$. 
"PTR" conditions (not highlighted in yellow) are identified for continuous improvement strategies like teacher re-training, recruitment etc. Thus in the event of teacher recruitment or need for reposting, this Model gives "location specific" decision support for most appropriate intervention (posting of new teachers or redeploying teachers).

\subsection{Number of Pupils Dropping Out of School}

Another indicator to influence the achievement of SDG 4: Qualitative Education is the number of drop outs/repetition. It is observed from Figure 5 that the entire drop outs from school greater than 20 pupils for the session (as highlighted in yellow) are all from Calabar south. This gives insight into the "location specific" intervention to ensure that pupils in Calabar South remain in school, while strategic planning for continuous improvement in enrolment and retaining of pupils in Calabar Municipality.

\subsection{Gender Parity}

A very important aspect of education is equity of access to education by all (male or females). Thus, Gender Parity Index (GPI) is a true measure of equal opportunity for all. GPI is a ration of male statistics to female statistics. When GPI is greater than 1, it shows statistics lopsided in favour of boys. Figure 6 shows highlighted schools where gender parity is greater than 1 (i.e. low female enrolment). This has implications for sustainable Education. The others schools not heighted in yellow are schools with equal gender parity or gender parity that is not lopsided against girl child education.

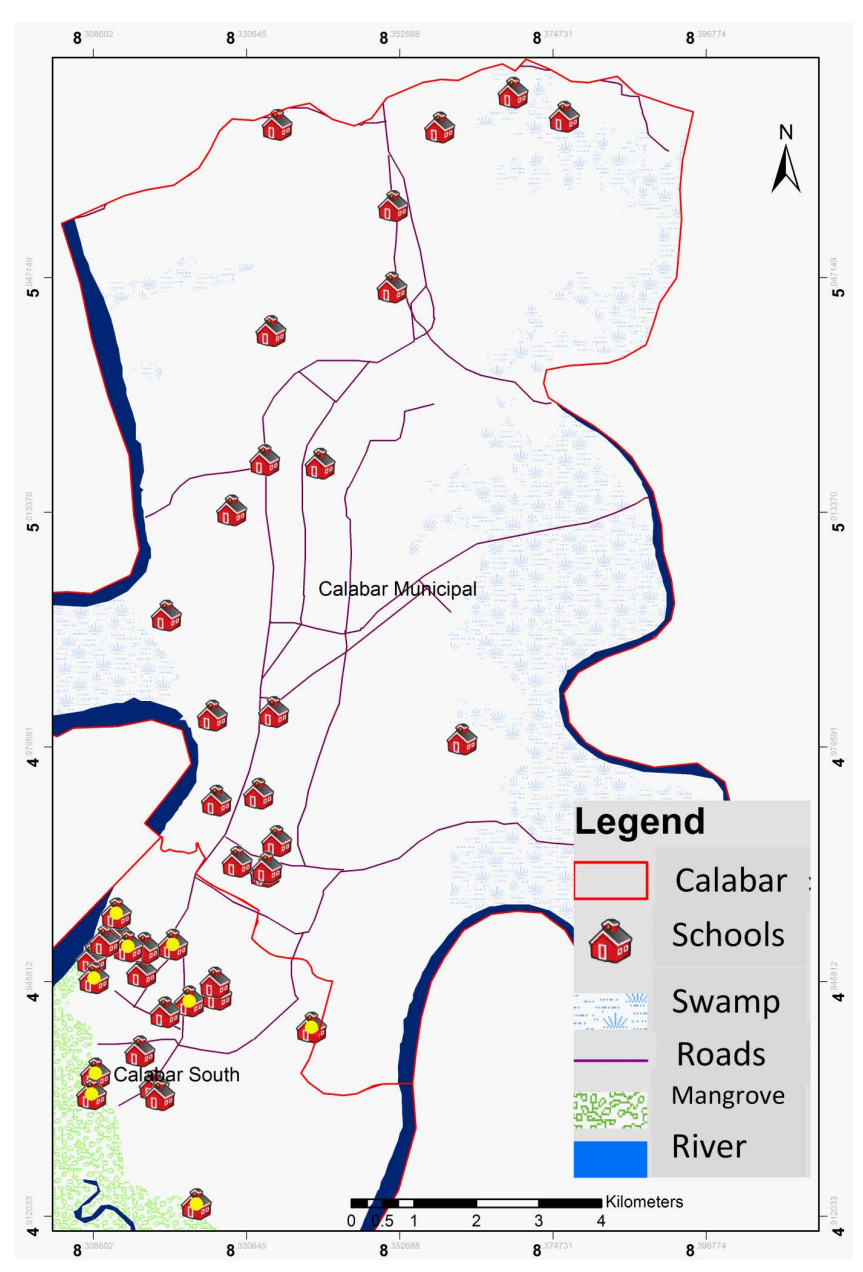

Figure 5. Highlighted Public primary schools (in yellow) where pupils drop out is more than 20 pupils per session per school. 


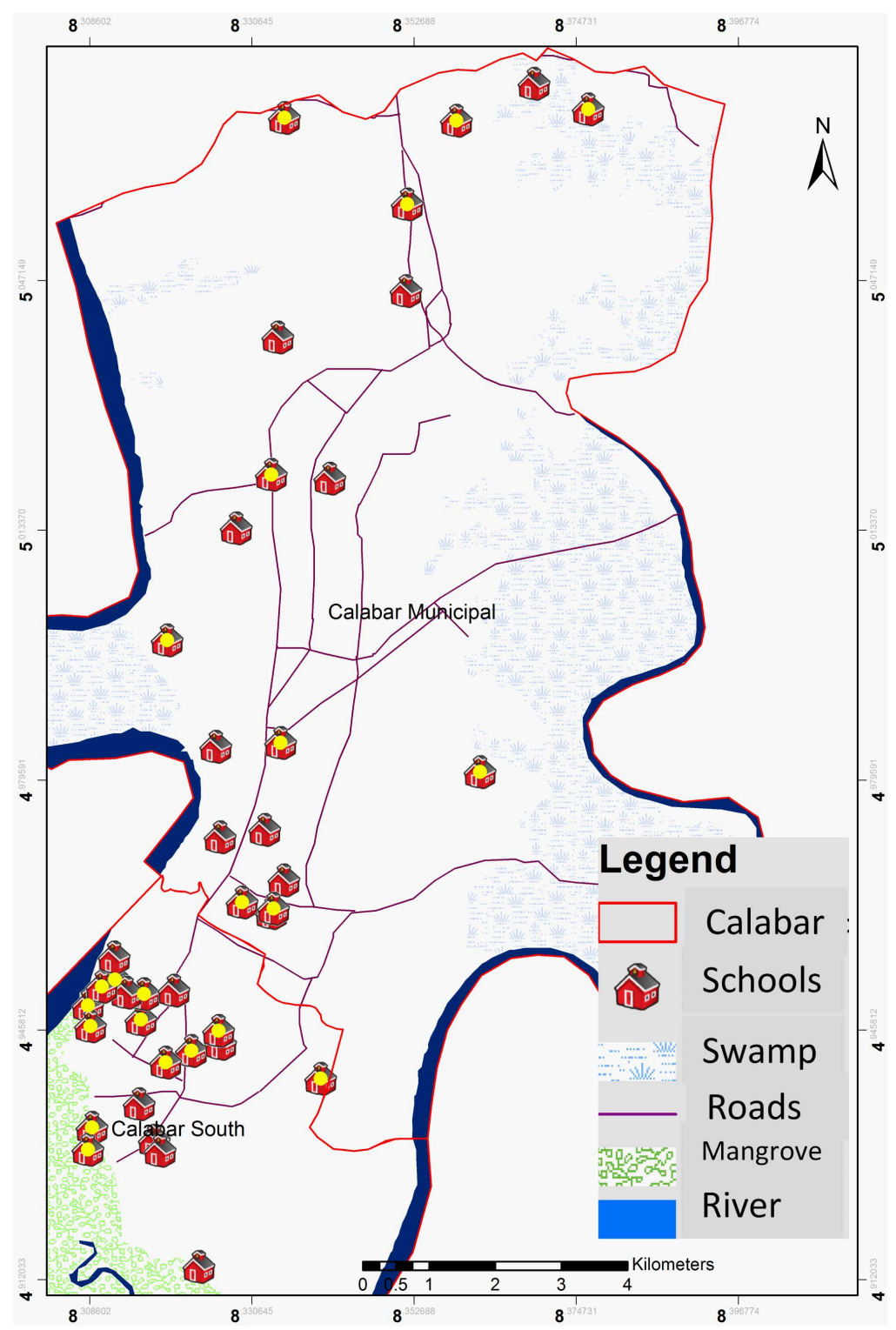

Figure 6. Highlighted Public primary schools (in yellow) where GPI is greater than 1 .

\section{Conclusion and Recommendations}

\subsection{Conclusion}

This paper tried to develop and propagate a new GIS based planning model that can answer the "where" questions by identifying areas requiring "location specific" interventions in order to specifically address small scale challenges of sustainable development. A Comparative Geospatial Planning Model for "Location Specific" Intervention and Continuous Improvement Strategy was developed and applied in SDG 4: Quality Education, to support decisions on locations requiring interventions. This is proven to be a useful tool for education administrators and decision makers.

\subsection{Recommendation}

Having successfully applied the Comparative Geospatial Planning Model for "Location Specific" Intervention and Continuous Improvement Strategy in education, it is hereby recommended that other applications in sustainable development areas like health care, environmental sustainability, conservation, etc. be attempted to en- 
sure the multi-sectorial applications and universal acceptance of the model.

\section{References}

[1] Miclat, E.F. (2005) Strategic Planning in Education: Making Change Happen. Rex Book Store, c2005, Manila, Accessed February 2014. http://trove.nla.gov.au/work/27292832?q=+\&versionId=32898833\#

[2] Naqvi, A.A. (2007) A Look at the Spatial Inequality in Pakistan: Case Study of District Sargodha. Paper Presented at Mapping Global Inequalities-Beyond Income Inequality, University of California, Santa Cruz.

[3] Worrall, L. (1991) Spatial Analysis and Spatial Policy Using Geographic Information System. Belhaven Press, New York.

[4] Zafar, M. and Yasir (2011) Use of Data for Education Planning and Management: Training Manual. AEPAM Publication No. 243, Islamabad, 34-43.

[5] Tibendra (2010) Application of GIS as Education Decision Support System: A Case Study of Higher Secondary Education in Nepal. Accessed September 2012.

[6] National Population Commission (2006) Population and Housing Census; Priority Table Volume IV, Population Distribution by Age \& Sex (State \& Local Government Area) Table DS5. NPC 2010, Abuja, Federal Republic of Nigeria.

[7] National Population Commission (Nigeria) and RTI International (2010) Nigeria Demographic and Health Survey (DHS) Ed Data Profile: Education Data for Decision-Making. National Population Commission and RTI International, Washington DC.

[8] UNESCO-UIS (2012) Global Demand for Primary Teachers-2012 Update; Projections to Reach Universal Primary Education by 2015. UNESCO-UIS Information Bulletin No. 10, Accessed September 2012.

[9] UNESCO-UIS (2009) Education Indicators Technical Guidelines. UNESCO-UIS Information Bulletin No. 14, Accessed September 2012.

[10] TRCN (2010) Professional Standards for Nigeria Teachers. Teachers Registration Council of Nigeria (Federal Ministry of Education), Accessed February 2014. http://www.trcn.gov.ng/PSNT\%202010.pdf 